\title{
Tropospheric ozone column retrieval at northern mid-latitudes from the Ozone Monitoring Instrument by means of a neural network algorithm
}

\author{
P. Sellitto ${ }^{1, *}$, B. R. Bojkov ${ }^{2}$, X. Liu ${ }^{3}$, K. Chance ${ }^{3}$, and F. Del Frate ${ }^{1}$ \\ ${ }^{1}$ Earth Observation Laboratory, Department of Computer, Systems and Industrial Engineering, Tor Vergata University, \\ Via del Politecnico 1, 00133 Rome, Italy \\ ${ }^{2}$ European Space Agency, Via Galileo Galilei, 00044 Frascati, Rome, Italy \\ ${ }^{3}$ Harvard-Smithsonian Center for Astrophysics, 60 Garden Street, MS-50, Cambridge, MA 02138, USA \\ * now at: Laboratoire Inter-universitaire des Systèmes Atmosphériques, CNRS UMR7583, Universités Paris-Est et Paris \\ Diderot, CNRS, 61 Avenue du Général de Gaulle, 94010 Créteil, France
}

Received: 22 March 2011 - Published in Atmos. Meas. Tech. Discuss.: 2 May 2011

Revised: 14 October 2011 - Accepted: 24 October 2011 - Published: 3 November 2011

\begin{abstract}
Monitoring tropospheric ozone from space is of critical importance in order to gain more thorough knowledge on phenomena affecting air quality and the greenhouse effect. Deriving information on tropospheric ozone from UV/VIS nadir satellite spectrometers is difficult owing to the weak sensitivity of the measured radiance spectra to variations of ozone in the troposphere. Here we propose an alternative method of analysis to retrieve tropospheric ozone columns from Ozone Monitoring Instrument radiances by means of a neural network algorithm. An extended set of ozone sonde measurements at northern mid-latitudes for the years 2004-2008 has been considered as the training and test data set. The design of the algorithm is extensively discussed. Our retrievals are compared to both tropospheric ozone residuals and optimal estimation retrievals over a similar independent test data set. Results show that our algorithm has comparable accuracy with respect to both correlative methods and its performance is slightly better over a subset containing only European ozone sonde stations. Possible sources of errors are analyzed. Finally, the capabilities of our algorithm to derive information on boundary layer ozone are studied and the results critically discussed.
\end{abstract}

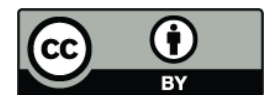

Correspondence to: P. Sellitto (pasquale.sellitto@lisa.u-pec.fr)

\section{Introduction}

Deviations of tropospheric ozone concentrations from background values have strong impacts on both climate and air quality. Tropospheric ozone levels are mainly determined by two processes: stratosphere-troposphere exchange (STE), and photochemical production (WMO, 2002). It has been estimated that the observed and modeled enhancement of tropospheric ozone derived from human activities (see, e.g. Logan et al., 1999; Vingarzan, 2004; Oltmans et al., 2006; Jonson et al., 2006) is the third major source of the greenhouse effect (IPCC, 2001; Shindell et al., 2009). High levels of ozone near the surface may also be a threat to human health and may damage crops (Seinfeld and Pandis, 1998; The Royal Society, 2008). Monitoring patterns of ozone at lower altitudes, and analyzing the possible interconnections with sources and sinks, is crucial to understand phenomena of a great importance for the life on Earth. For these reasons, monitoring ozone concentrations and trends, especially in the troposphere, is a relevant topic in recent geoscience research.

Observing height-resolved atmospheric ozone, with a particular emphasys at the troposphere, from satellites is thus an exciting advance. UV/VIS nadir sensors, e.g. the Solar Backscatter Ultraviolet (SBUV) instruments, the Global Ozone Monitoring Experiment (GOME), the SCanning Imaging Absorption SpectroMeter for Atmospheric

Published by Copernicus Publications on behalf of the European Geosciences Union. 
CHartographY (SCIAMACHY), the EOS-Aura Ozone Monitoring Instrument (OMI) and the MetOp GOME-2, are particularly useful for this. Also, infrared sensors, including the Tropospheric Emission Spectrometer (TES) and the Infrared Atmospheric Sounding Interferometer (IASI) can be used to derive tropospheric ozone from space. The OMI instrument provides a particularly good opportunity to contribute to the understanding of ozone-related phenomena in the troposphere, owing to the relatively small pixel size at the near-nadir portion of its measurement swath; it is also useful for efficient monitoring owing to its daily global coverage (Levelt et al., 2006).

Different techniques have been recently proposed to monitor tropospheric ozone from satellites including OMI: see, e.g. the methods proposed by Ziemke et al. (2006a,b); Yang et al. (2007); Schoeberl et al. (2007); Stajner et al. (2008); Liu et al. (2010b). Three major techniques exist within this field. The first is the tropospheric ozone residual (TOR) technique (first introduced by Fishman and Larsen, 1987 and then applied to OMI data by Ziemke et al., 2006b; Schoeberl et al., 2007): the stratospheric ozone column, which can be measured with a limb sounder like the Microwave Limb Sounder (MLS), is subtracted from a co-located total column ozone measurement, which can be acquired with a nadir instrument like OMI. In this case, one must deal with measurements from two different sensors considering issues related to non-homogeneous data sets. The horizontal resolution may be degraded by the use of limb measurements, which have lower horizontal resolution and/or horizontal coverage than nadir observations. The second technique is the convective cloud differential method (Ziemke et al., 1998; Valks et al., 2003). This methodology is based on the knowledge of the cloud top pressure to separate the stratosphere from the troposphere. This method has the drawback of being limited to regions with deep convective clouds and generally not applied to individual satellite pixels, but used to derive monthly means. The third technique is based on optimal estimation (OE) (Rodgers, 2000) to retrieve height-resolved ozone concentrations, including the troposphere (see, e.g. the papers by Munro et al., 1998; Liu et al., 2010b). OE relies on the use of a forward radiative transfer model, which requires substantial computation. It may be susceptible to model errors in the presence of aerosols and clouds. It requires the radiance spectra to be accurately calibrated.

Neural network (NN) algorithms have demonstrated encouraging capabilities as an alternative tool to retrieve height-resolved ozone concentrations from satellite data, (see, e.g. Del Frate et al., 2002, 2005; Müller et al., 2003; Iapaolo et al., 2005; Sellitto et al., 2011). Recently, NN algorithms for both ozone profile retrieval (e.g. Sellitto et al., 2007b, 2011), and tropospheric ozone column retrievals, (e.g. Sellitto et al., 2007a) from SCIAMACHY have been developed. Some first experiments have been done for stratospheric and upper tropospheric ozone profile retrieval from OMI (Sellitto et al., 2008). NNs have several advantages over the TOR and the OE techniques in this application: they learn the inverse relationship between the radiance spectra and the tropospheric ozone column (TOC) from a set of sample data so that a direct model is not necessary. They are expected to be less sensitive than $\mathrm{OE}$ to systematic errors of input spectra, and to clouds and aerosols. Once trained, a NN is able to operate in real time. However, its performances depend on the quality of the training set and a statistically complete set of external measurements is not always available.

We present the OMI-TOC NN, a NN algorithm to retrieve TOCs from OMI Level $1 \mathrm{~b}$ data.

In Sects. 2.1 and 2.2 brief overviews of NNs and OMI are given. Sections 2.3 and 2.4 introduce and discuss the available data set and the general methodology to train and test our NN algorithm. Results are presented in Sect. 3, including a comparison of our retrievals with those of Liu et al. (2010b) and Schoeberl et al. (2007). We address the causes of error for our retrievals (Sect. 4.1) and evaluate the capability of the OMI-TOC NN to detect ozone information at the lowest altitude levels (Sect. 4.2). Section 5 presents conclusions.

\section{Data and methodology}

\subsection{Neural networks algorithms}

An artificial neural network (NN) is a mathematical model able to extract the underlying relationships between input and output quantities by means of a learning stage. During this stage, a set of experimental or simulated input-output pairs is given to the NN to train the model. NNs are based on biological nervous systems, and, as such, are organized as parallel structures. A NN is composed by elementary processing units, called neurons, linked by weighted synapses. The neurons can be organized in layers, e.g. one input layer that receives the input quantities, one or more hidden layers, and an output layer that gives the output quantities. If the information flows only from input to hidden to output layers, the model is called a feedforward NN. Each neuron in a layer receives the signal from all the outputs of the neurons of the previous layer, in the form of a weighted sum, whose weights are the parameters associated to the synapses connecting one neuron to the neurons of the previous layer. The input signal to one neuron is then processed with an activation function (AF) to produce the output of the neuron, which will be fed to the next layer. Non-linear AFs, e.g. squashing sigmoidal functions, are usually used. During the learning stage, a set of input-output pairs is presented to the NN. It is possible to define an error function to measure the differences between the true output values and the outputs that are calculated by the NN model. From the analysis of the gradient vector in the error hypersurface it is then possible to define some criteria to adjust the weight parameters to make the model learn the underlying relationships between input and output quantities. Comprehensive theoretical descriptions of NNs are found in 


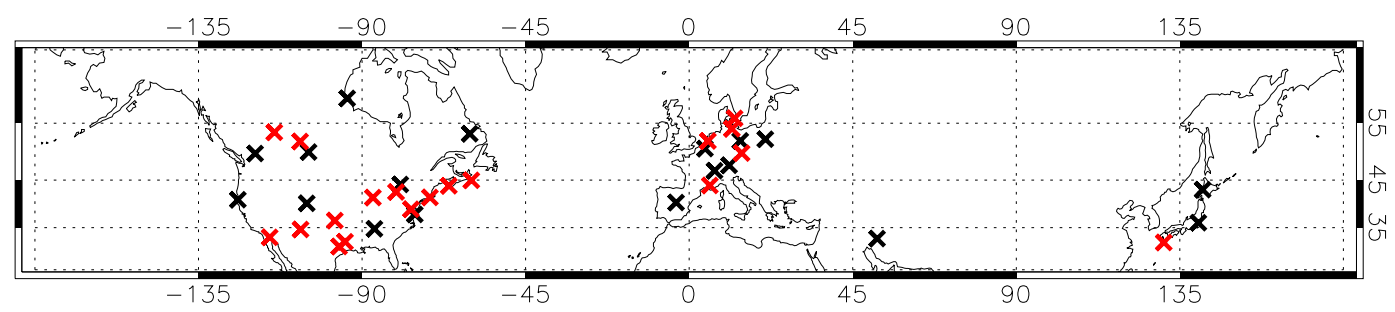

Fig. 1. Geographical distribution of the OS stations at mid-latitudes. Black and red stations are used for training and test, respectively.

(Bishop, 1995; Haykin, 1999; Kecman, 2001), while a rigorous demonstration that NNs are universal approximators is given by Hornik et al. (1989).

\subsection{The EOS-Aura Ozone Monitoring Instrument}

The Ozone Monitoring Instrument (OMI) is a contribution of the Netherlands and Finland to NASA's Aura mission. OMI is a nadir-viewing pushbroom spectrometer that operates in the UV/VIS spectral range ( 270 to $500 \mathrm{~nm}$ ), with a spectral resolution of $0.42-0.63 \mathrm{~nm}$ and a direct nadir spatial resolution of $13 \mathrm{~km}$ along track $\times 24 \mathrm{~km}$ across track (the spatial resolution at the ends of the swath is substantially larger) (Levelt et al., 2006). The wide $\left(114^{\circ}\right)$ field of view of the telescope corresponds to a $2600 \mathrm{~km}$ wide swath on the surface, which make it possible a daily global coverage. The light entering the telescope is depolarized using a scrambler and then split into two channels: the ultraviolet (UV) channel (wavelength range 270-380 nm) and the visible (VIS) channel (wavelength range $350-500 \mathrm{~nm}$ ). The OMI heritage is the European Space Agency Global Ozone Monitoring Instrument (GOME) (Burrows et al., 1999) and the SCanning Imaging Absorption SpectroMeter for Atmospheric CHartographY (SCIAMACHY) (Bovensmann et al., 1999) instruments, which introduced the concept of measuring the complete spectrum in the UV/VIS/NIR wavelength range with moderate spectral resolution. The high spatial and moderate spectral resolutions are simultaneously possible for the OMI by the use of a two-dimensional detector. The small pixel size in principle enables OMI to have more cloud free pixels. Pixels affected by row anomalies (http://www.knmi. nl/omi/research/product/rowanomaly-background.php), after May 2007, have been implicitly filtered out and then not used within our work, based on a threshold on fitting residuals for the correlative OE algorithm (see Sect. 3).

\subsection{Training and test data}

The topology of our OMI-TOC NN algorithm, which will be more thoroughly described in Sect. 2.4, includes an input layer taking the OMI Level $1 \mathrm{~b}$ normalized radiances at selected wavelengths, with some additional information, e.g. the total ozone column from the OMTO3 operational OMI Level 2 product (Bhartia and Wellemeyer, 2002), and an output layer yielding the TOC (surface-200 hPa). During the training/test phase, several input-output pairs are given to the net. For the output, TOCs are obtained from co-located ozone sonde (OS) measurements. We have a limitation based on the available output data in forming a large set of inputoutput pairs to train and test the net. We chose as truth reference the extended ozone sondes data set also used by Schoeberl et al. (2007), covering the years 2004-2008 and obtained from the Aura Validation Data Center (AVDC).

As stated by Hornik et al. (1989), a NN can approximate an unknown functional relationship as long as the training data set is sufficiently large, i.e. statistically representative of the retrieved quantities. In our case it is necessary for the data set to cover the inherent ozone climatology. Ozone sonde launches are relatively expensive and sparse both in time and in space, so it is difficult to build a significant data set to train a NN algorithm. Our approach is to limit the data set in space, to avoid confusion into the learning phase by giving the $\mathrm{NN}$ a large number of different climatologies: we restrict our development to northern mid-latitudes, $30^{\circ} \mathrm{N}-$ $60^{\circ} \mathrm{N}$. Figure 1 shows the distribution of the training and test stations. The overall number of the available ozone sonde stations is 37 . They cover different periods each, but overall from the end of 2004 to April 2008.

We subdivide the available ozone sonde stations by considering their climatological and campaign-based nature. The criterion of this subdivision is related to the continuity of the available measurements for each station: stations that operated continuously are considered climatological while stations that operated less continuously are considered campaign-based. Some of these latter come from measurement campaigns, e.g. the INTEX-B Ozonesonde Network Study 2006 (IONS-06) (http://croc.gsfc.nasa.gov/ intexb/ions06.html) (Thompson et al., 2003).

Following this subdivision, we use the climatological stations to generate the training data set and the campaignbased stations for the test data set. This is done to maintain the two data sets as independently as possible. Campaignbased stations are often operating in locations or periods of time with peculiar climatologies, e.g. high altitude stations, so that testing the performance of the $\mathrm{NN}$ with these measurements gives an indication of the generalization capability of the algorithm, with conditions that are not present in the training data set. Table 1 summarizes the number of measurements for every ozone sonde station in America, 
Table 1. Available OS stations.

\begin{tabular}{|c|c|c|c|c|}
\hline Name & Typology & Number of available measurements & Latitude & Longitude \\
\hline Boulder & Climatological/Training & 95 & $40.0^{\circ} \mathrm{N}$ & $105.2^{\circ} \mathrm{W}$ \\
\hline Bratts Lake & Climatological/Training & 108 & $50.2^{\circ} \mathrm{N}$ & $104.7^{\circ} \mathrm{W}$ \\
\hline Churchill & Climatological/Training & 91 & $58.7^{\circ} \mathrm{N}$ & $94.1^{\circ} \mathrm{W}$ \\
\hline Egbert & Climatological/Training & 103 & $44.2^{\circ} \mathrm{N}$ & $79.8^{\circ} \mathrm{W}$ \\
\hline Goose Bay & Climatological/Training & 126 & $53.3^{\circ} \mathrm{N}$ & $60.4^{\circ} \mathrm{W}$ \\
\hline Huntsville & Climatological/Training & 82 & $34.7^{\circ} \mathrm{N}$ & $86.6^{\circ} \mathrm{W}$ \\
\hline Kelowna & Climatological/Training & 116 & $49.3^{\circ} \mathrm{N}$ & $119.4^{\circ} \mathrm{W}$ \\
\hline Trinidad Head & Climatological/Training & 57 & $40.8^{\circ} \mathrm{N}$ & $124.2^{\circ} \mathrm{W}$ \\
\hline Wallops Island & Climatological/Training & 159 & $37.9^{\circ} \mathrm{N}$ & $66.1^{\circ} \mathrm{W}$ \\
\hline Beaumont & Campaign-based/Test & 3 & $30.1^{\circ} \mathrm{N}$ & $94.1^{\circ} \mathrm{W}$ \\
\hline Beltsville & Campaign-based/Test & 10 & $39.0^{\circ} \mathrm{N}$ & $76.5^{\circ} \mathrm{W}$ \\
\hline College Station & Campaign-based/Test & 1 & $30.6^{\circ} \mathrm{N}$ & $96.3^{\circ} \mathrm{W}$ \\
\hline Edmonton & Campaign-based/Test & 99 & $53.5^{\circ} \mathrm{N}$ & $114.1^{\circ} \mathrm{W}$ \\
\hline Holtville & Campaign-based/Test & 15 & $32.8^{\circ} \mathrm{N}$ & $115.4^{\circ} \mathrm{W}$ \\
\hline Houston & Campaign-based/Test & 52 & $29.7^{\circ} \mathrm{N}$ & $95.4^{\circ} \mathrm{W}$ \\
\hline Lamont & Campaign-based/Test & 15 & $36.7^{\circ} \mathrm{N}$ & $97.6^{\circ} \mathrm{W}$ \\
\hline Narragansett & Campaign-based/Test & 73 & $41.5^{\circ} \mathrm{N}$ & $71.4^{\circ} \mathrm{W}$ \\
\hline Sable Island & Campaign-based/Test & 25 & $43.9^{\circ} \mathrm{N}$ & $60.0^{\circ} \mathrm{W}$ \\
\hline Socorro & Campaign-based/Test & 22 & $36.4^{\circ} \mathrm{N}$ & $106.9^{\circ} \mathrm{W}$ \\
\hline Vanscoy & Campaign-based/Test & 1 & $52.0^{\circ} \mathrm{N}$ & $107.0^{\circ} \mathrm{W}$ \\
\hline Walsingham & Campaign-based/Test & 18 & $42.6^{\circ} \mathrm{N}$ & $80.6^{\circ} \mathrm{W}$ \\
\hline Yarmouth & Campaign-based/Test & 79 & $43.9^{\circ} \mathrm{N}$ & $66.1^{\circ} \mathrm{W}$ \\
\hline Barajas & Climatological/Training & 107 & $40.5^{\circ} \mathrm{N}$ & $3.6^{\circ} \mathrm{W}$ \\
\hline Hohenpeissenberg & Climatological/Training & 360 & $47.8^{\circ} \mathrm{N}$ & $11.0^{\circ} \mathrm{E}$ \\
\hline Legionowo & Climatological/Training & 179 & $52.4^{\circ} \mathrm{N}$ & $21.0^{\circ} \mathrm{E}$ \\
\hline Lindenberg & Climatological/Training & 161 & $52.2^{\circ} \mathrm{N}$ & $14.1^{\circ} \mathrm{E}$ \\
\hline Payerne & Climatological/Training & 463 & $46.5^{\circ} \mathrm{N}$ & $6.6^{\circ} \mathrm{E}$ \\
\hline Uccle & Climatological/Training & 390 & $50.8^{\circ} \mathrm{N}$ & $4.3^{\circ} \mathrm{E}$ \\
\hline De Bilt & Campaign-based/Test & 120 & $52.1^{\circ} \mathrm{N}$ & $5.2^{\circ} \mathrm{E}$ \\
\hline Haute Provence & Campaign-based/Test & 2 & $43.9^{\circ} \mathrm{N}$ & $5.7^{\circ} \mathrm{E}$ \\
\hline Jaegersborg & Campaign-based/Test & 2 & $55.8^{\circ} \mathrm{N}$ & $12.5 \mathrm{E}$ \\
\hline Kuehlungsborn & Campaign-based/Test & 10 & $54.0^{\circ} \mathrm{N}$ & $11.6^{\circ} \mathrm{E}$ \\
\hline Prague & Campaign-based/Test & 133 & $50.0^{\circ} \mathrm{N}$ & $14.4^{\circ} \mathrm{E}$ \\
\hline Isfahan & Climatological/Training & 36 & $32.5^{\circ} \mathrm{N}$ & $51.7^{\circ} \mathrm{E}$ \\
\hline Sapporo & Climatological/Training & 117 & $43.1^{\circ} \mathrm{N}$ & $141.3^{\circ} \mathrm{E}$ \\
\hline Tateno & Climatological/Training & 120 & $36.0^{\circ} \mathrm{N}$ & $140.1^{\circ} \mathrm{E}$ \\
\hline Kagoshima & Campaign-based/Test & 21 & $31.6^{\circ} \mathrm{N}$ & $130.6^{\circ} \mathrm{E}$ \\
\hline
\end{tabular}

Europe and Asia. We do not assign all measurements deriving from actual campaigns to the campaign-based category. For example, Egbert station, Ontario, Canada, operated in the framework of the IONS-06 campaign but we used it for training because of the relevant number of measurements (103, see Table 1) in an area with little ozone sonde coverage. This is done to maintain reasonable statistics in both the training and test data sets; if a stricter subdivision was made, we might have unbalanced training/test data sets, e.g. in America we might have more test than training samples, while a ratio of about $75 \%$ (training) to $25 \%$ (test) is desirable (Hornik et al., 1989).

A matching procedure is implemented to create the input-output pairs for the OMI-TOC NN. OMI pixels are considered to match with ozone sonde launches if data are collected within a maximum time interval of $12 \mathrm{~h}$ with respect to the OMI overpass, and if the station is contained within the OMI pixel.

We obtained about 4500 input-output samples, with $75 \%$ in the training data set and $25 \%$ in the test data set. We train one NN with the whole mid-latitudes data set: adaptive approaches to define different NN algorithms for America, Europe and Asia are under investigation.

\subsection{Algorithm configuration}

Once the training and test data sets have been generated, additional configuration issues must be considered, and then 
the net must be trained. Our neural processing chain, which has been described in e.g. Del Frate et al. $(2002,2005)$ and is applied here, relies on two separate phases. The first one is off-line and gives as output the values of the network parameters. The second one is operational and completely automatic and yields the estimated quantities, i.e. the output. A brief description of each step of the OMI-TOC NN processing chain, and how it is practically applied, follows.

Since OMI measures radiances at many wavelengths, we need to select the most informative wavelengths to use in the retrieval, minimizing the ill-conditioning of the inversion problem (Twomey, 1996). Automatic wavelength selection has the purpose of lowering the number of elements that characterize the input of the net while preserving as much information as possible. This is achieved by an extended pruning (EP) procedure (Del Frate et al., 2005) that is performed after a preliminary screening of the sensitive sub-bands done with a radiative transfer model (Sellitto et al., 2011). Normally, a pruning procedure is applied to a trained net to optimize its structure. The network is examined to assess the relative importance of its weights, and the least important ones are deleted. This is followed by further training of the pruned network: the pruning and training may be repeated for several cycles. In order to select the most convenient inputs for an application, the EP procedure is prolonged to the input layer. The EP scheme is summarized as follows: (1) a net with a maximum input dimensionality is trained; (2) the synapse with the lowest magnitude is pruned; (3) the net is retrained without re-initialization and with a lower number of training cycles; (4) the training error $E$ is evaluated: if $E$ is larger than a threshold value $E_{\mathrm{thr}}$ then the pruning in stopped, otherwise the algorithm restarts from point (2). In this phase only measurements from the UV channel are considered. $19 \mathrm{UV}$ wavelengths are selected, in the ranges $305-307 \mathrm{~nm}$ and $322-325 \mathrm{~nm}$. They are in approximately the same spectral intervals used for SCIAMACHY TOC retrievals (Sellitto et al., 2011). Sellitto et al. (2011) describes the physical importance of the selected wavelengths. The spectral input quantities are the ratios of the UV Earth's radiance spectra (global mode), taken from the OML1BRUG product, with respect to the corresponding solar irradiance spectra, taken from the OML1BIRR product, at the 19 selected wavelengths. The radiance spectra are normalized by the solar irradiance in order to limit the effects of instrumental parameters on the spectral shape. The input vector also includes the solar zenith angle (SZA), to take into consideration the geometry of observation, and the total column ozone from coincident OMI Level 2 data, from the OMTO3 collection 3 v8.5 product (Bhartia and Wellemeyer, 2002), which is based on the Total Ozone Mapping Spectrometer (TOMS) v8 total ozone algorithm. The OMTO3 derived ozone columns have been extensively validated (McPeters et al., 2008). The value of the total column ozone is expected to act as a regularization parameter when used into the input vector of our net. We compared the results of our algorithm with those from a NN with the same input vector and topology definitions, and trained and tested over the same data sets, but without the total ozone in input. We found that the performances of this latter algorithm are more than $20 \%$ worse in terms of both the correlation coefficient and the RMS deviations of retrieved versus reference OS TOCs over the test data set. The output quantities are the TOCs from the integration of the ozone concentrations derived from ozone sonde measurements, from the surface to $200 \mathrm{hPa}$. Please note that, differently from physically-based methods, NNs do not allow the calculation of averaging kernels and so a formal definition of the vertical sensitivity of the output cannot be given here. Input and output quantities are linearly scaled, between -1 and 1 and between 0 and 1, respectively, to let the AFs of the $\mathrm{NN}$ to operate within their optimal interval of acceptance.

To improve the general applicability of the algorithm, the different seasonal and regional effects have to be considered and the learning and test sets have to be generated with a statistically significant number of patterns. Moreover, statistical independence between the training and the test set has to be assured to avoid limiting the robustness of the network. The independence of the training and test data sets is reasonably assured for OMI-TOC NN by using the climatological and campaign-based stations, respectively, for them.

NN models are mainly specified by the net topology and training rules (Bishop, 1995). The term topology refers to the structure of the network as a whole: the number of its input, output, and hidden units and how they are interconnected. Among various topologies, we have found that a multi-layer perceptron (MLP) has the best-suited topology for our inversions. The hidden layer structure providing the optimal performance is selected. If the number of neurons is too small, the input-output associative capabilities of the net are too weak. If it is too large, the capability can be being tailored too much on the training set, and the computational complexity of the algorithm does not improve its applicability. We optimize the algorithm using a heuristic approach, systematically analyzing the network performance when varying either the number of hidden layers (one or two) or the number of hidden units and selecting the best topology on the basis of the accuracy of the obtained results on a set of samples not used for training. We use the early stopping method to determine when to stop the training. According to this criterion, the performance of the net during the training phase is evaluated either on the training set or on an independent test set. In the training set, the overall error keeps decreasing with the training epochs, approaching a value of convergence. Conversely, the error on the test set reaches a minimum value, after which it starts increasing if we continue the training operations. At this point the learning phase is interrupted. We select a 21-21-1 topology for the OMI-TOC NN, with main characteristics given in Fig. 2. The scaled conjugate gradient (SCG) method is chosen for the training algorithm. It is expected to converge in a shorter time then standard error back-propagation procedures (Møller, 1993). Indeed, we 


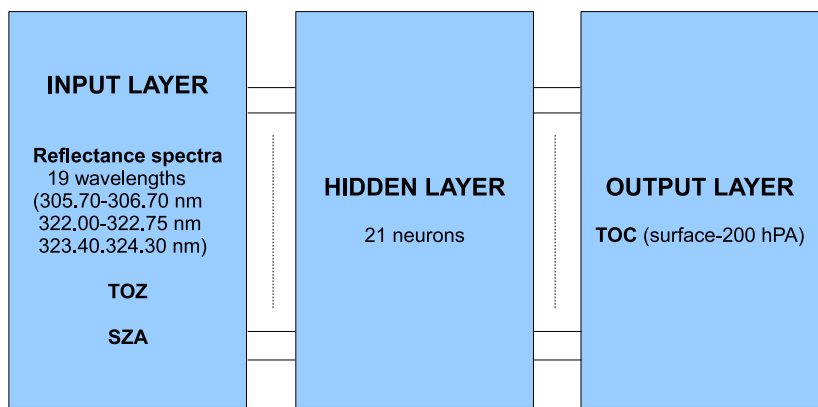

Fig. 2. General scheme, including topology, of the OMI-TOC NN algorithm.

reach a minimum value for the training error in only about 1500 epochs.

The previously described off-line phase provides the network parameters (topology and weights). Once these determined, the retrieval proceeds via a fully automatic, realtime processing chain. The pre- and post-processing modules only apply (de)normalization procedures. The neural implementation itself is very fast, and requires minimal computational capability. The software implementation is done with the Interactive Data Language (IDL) tool from ITT Visual Information Solutions. Running on a personal computer with modest technical specifications (1 double core $2.26 \mathrm{GHz}$ CPU with a 4 GB RAM), it requires less than $1 \mathrm{~min}$ to analyze a full day of measurements (15 OML1BRUG orbit files, 42000 pixels per orbit), once the data are extracted.

\section{Results and comparisons with OE and TOR}

OMI-TOC NN retrievals are compared to the reference colocated ozone sonde measurements for the test data set at campaign-based stations. Figure 3 is a scatter plot showing NN retrievals versus sonde data. Data at different seasons are indicated by different colors. In Fig. 4 we show similar results, but obtained from only cloud-free pixels (both training and test data sets have been screened for cloudy pixels). The criterion for cloud-free pixels is the same one used by Schoeberl et al. (2007) and Liu et al. (2010b): a pixel is considered as cloud contaminated if the effective cloud fraction is greater than 0.3. The cloud fraction information is derived from co-located OMTO3 data. Comparing the two scatter plots and the correlation coefficients therein, the OMI-TOC NN algorithm is substantially insensitive to clouds. Further investigations to fully understand the reasons for this behaviour are currently ongoing.

The statistical characterization of this data set can be compared with the similar scatter plot analysis reported in Fig. 4 of Schoeberl et al. (2007), where mid-latitude TOC retrievals with a TOR algorithm using OMI and MLS ("Schoeberl algorithm TOCs") are reported and compared with co-located

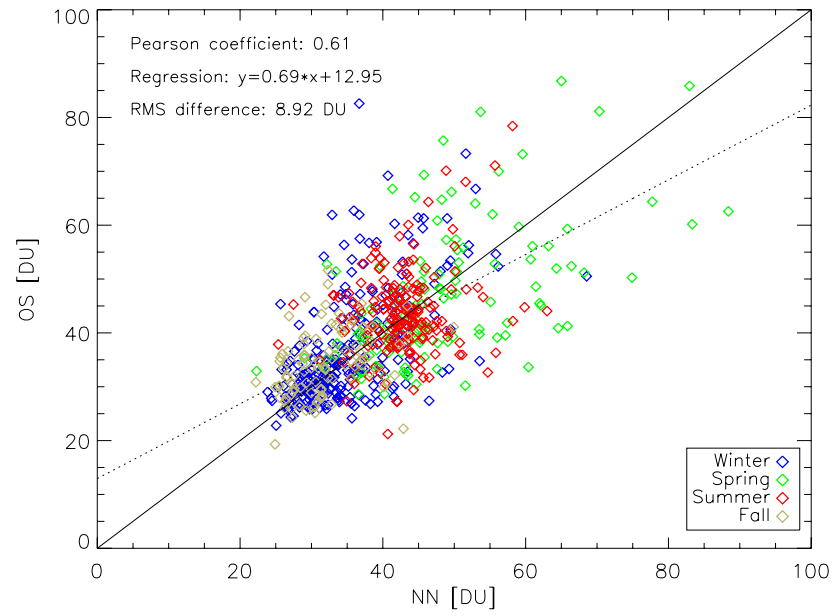

Fig. 3. Scatter plot of OMI-TOC NN retrievals versus corresponding OS TOCs for the test data set. Seasons are plotted in different colors (see legend).

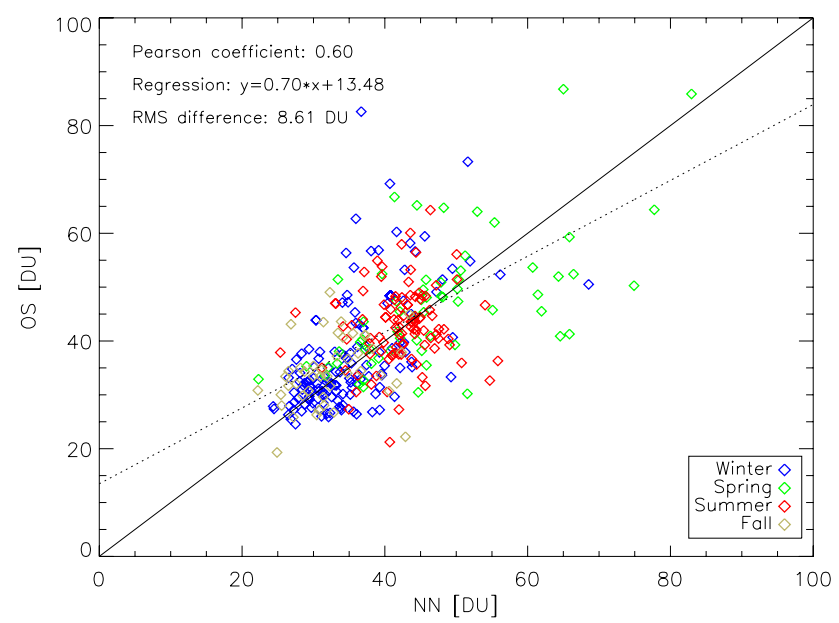

Fig. 4. Scatter plot of OMI-TOC NN retrievals versus corresponding OS TOCs for the test data set, in cloud-free conditions. Seasons are plotted in different colors (see legend).

ozone sonde measurements. From Figs. 3 and 4, the OMITOC NN correlation is comparable to that of Schoeberl et al. (2007), with Pearson coefficients of 0.61/0.60 (Schoeberl's are $0.45-0.68$, depending on the season) and root mean square (RMS) differences of 8.92/8.61 DU (Schoeberl's RMS differences are 8.7-13 DU, depending on the season), while the OMI-TOC NN's regression is better, having slope and intercept of 0.69/0.70 and 12.95/13.48 (Schoeberl's slope is $0.36-0.52$, depending on the season, while the intercept is not reported but from visual inspection seems larger than for our algorithm). The seasonal effect which is apparent in the TOR methodology is not present in our NN.

The OMI-TOC NN retrievals are compared with colocated TOCs from the now well-established OMI ozone 
profile product from OE (Liu et al., 2010b); This product has been validated in the stratosphere with co-located MLS profiles (Liu et al., 2010a). The OE-based profiles are integrated from the surface to $200 \mathrm{hPa}$ to produce a data set of TOCs ("Liu algorithm TOCs") which is comparable to the NN TOCs. Retrievals from both algorithms are compared to co-located ozone sonde TOCs, taken as a reference. Figure 5 shows a histogram of the absolute deviations of our retrievals and those from the Liu algorithm, with respect to the reference data. A symmetrical distribution is obtained for OMI-TOC NN, with no systematic differences, while a systematic difference is present both for Liu algorithm retrievals (about 2 DU) and Schoeberl algorithm retrievals (from about $3 \mathrm{DU}$ to more than $5 \mathrm{DU}$, depending on the season); this latter result can be seen in Fig. 4 of Schoeberl et al. (2007). The NN results should be unbiased by definition as they are derived from OS measurements. The Liu and the Schoeberl systematic differences reflect physical retrievals which are independent from the OS measurements. The standard deviation of the absolute differences is about 8.5-9.0 DU for both NNs, and Liu and Schoeberl algorithms (the latter in summer and fall seasons; for the Schoeberl algorithm in winter and spring, significantly higher values, up to $13 \mathrm{DU}$ are observed). The percent RMS deviation for NN is about $20 \%$, slightly lower than for the Liu algorithm. From a Student's ttest analysis, the Liu algorithm TOC distribution has a higher mean, 4.42 DU at a $p=1.08 \times 10^{-5}$ level, compared to the OMI-TOC NN retrievals. Please note that the retrievals are not filtered out for extreme off-nadir positions (which cause large systematic biases due to inadequate radiometric calibration) and cloudy pixels: the standard deviation is reduced by 1.3 DU for the Liu algorithm when these factors are considered.

Comparisons are presented for the overall European data set (Fig. 6), from two European test stations (De Bilt, the Netherlands in Fig. 7) and Prague, Czech Republic in Fig. 8), and from the only Asian test station, Kagoshima, Japan (Fig. 9). For every comparison at a single ozone sonde station the time series of OMI-TOC NN and Liu algorithm TOC retrievals, and of ozone sonde TOC reference values, are reported to show how NNs are capable to catch temporal trends of the TOCs. In each plot, the monthly mean TOCs from the three sources of data, with standard deviations, are also included. Plots of the time series of absolute differences of $\mathrm{NN}$ and Liu algorithm retrievals with respect to ozone sonde measurements, including monthly means, are also shown for each station. Finally, a comparison of scatter plots of NN versus ozone sonde and Liu algorithm TOCs versus ozone sonde is given for these stations. For the overall European data set, a histogram of absolute differences is also reported for the two methodologies.

From Fig. 6a and b, the OMI-TOC NN shows better agreement with sondes, by about $1 \mathrm{DU}$ for the RMS difference than the Liu algorithm, in Europe. The better agreement of the $\mathrm{NN}$ over European ozone sonde stations is also clear from

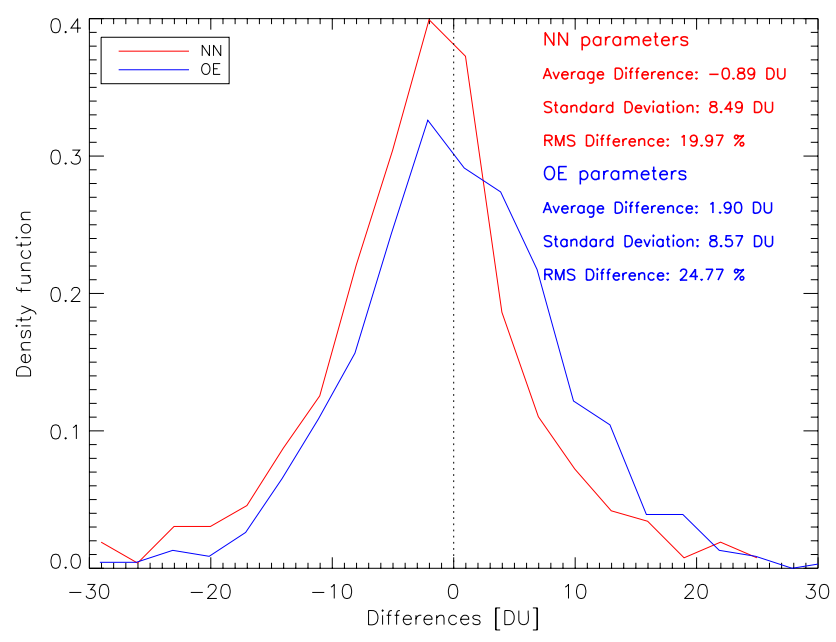

Fig. 5. Histogram of the absolute deviations of OMI-TOC NN (in red) and OE TOC (in blue) retrievals from the OS reference values for the test data set. OE TOCs are derived from the algorithm described in Liu et al. (2010b). Statistical parameters are also reported in red and blue, respectively.

the histograms in Figs. 5 and $6 \mathrm{c}$ and the statistical parameters therein. In particular, in Europe the distribution of the absolute differences of the $\mathrm{NN}$ with respect to reference ozone sonde TOC values, in addition to being unbiased, shows lower standard deviation (8.25 DU) and a percent RMS difference with values almost as low as $20 \%$. From a Student's t-test analysis, the Liu algorithm TOC distribution has a higher mean, $4.96 \mathrm{DU}$ at a $p=9.57 \times 10^{-7}$ level, with respect to OMI-TOC NN retrievals. The complete time series of the TOCs at the different stations being considered are shown in Figs. 7a, 8a and 9a, while the time series of the absolute differences with respect to the ozone sonde reference data are shown in Figs. 7b, $8 \mathrm{~b}$ and $9 \mathrm{~b}$. OS data are missing at De Bilt for most of the year 2007, so they are excluded from the comparisons. Although the time trends are generally well reproduced, in some time periods the Liu algorithm gives substantially larger values, e.g. from December 2004 to March 2005 and from December 2007 to February 2008 at De Bilt (Fig. 7a and 7b) and from January to March 2008 at Prague (Fig. 8a and 8b). Some periods of marked disagreement also occur for NN, e.g. the marked overestimation during March 2007 at Prague. From the scatter plots in Figs. $7 c-d, 8 c-d$ and $9 c-d$ the NN performances shows better agreements with sondes than the Liu algorithm at De Bilt and Prague, while at Kagoshima they are comparable. Over American locations, Liu has slightly better agreement with sondes than the OMI-TOC NN. In general, these two algorithms have comparable agreement over the worldwide data set. 

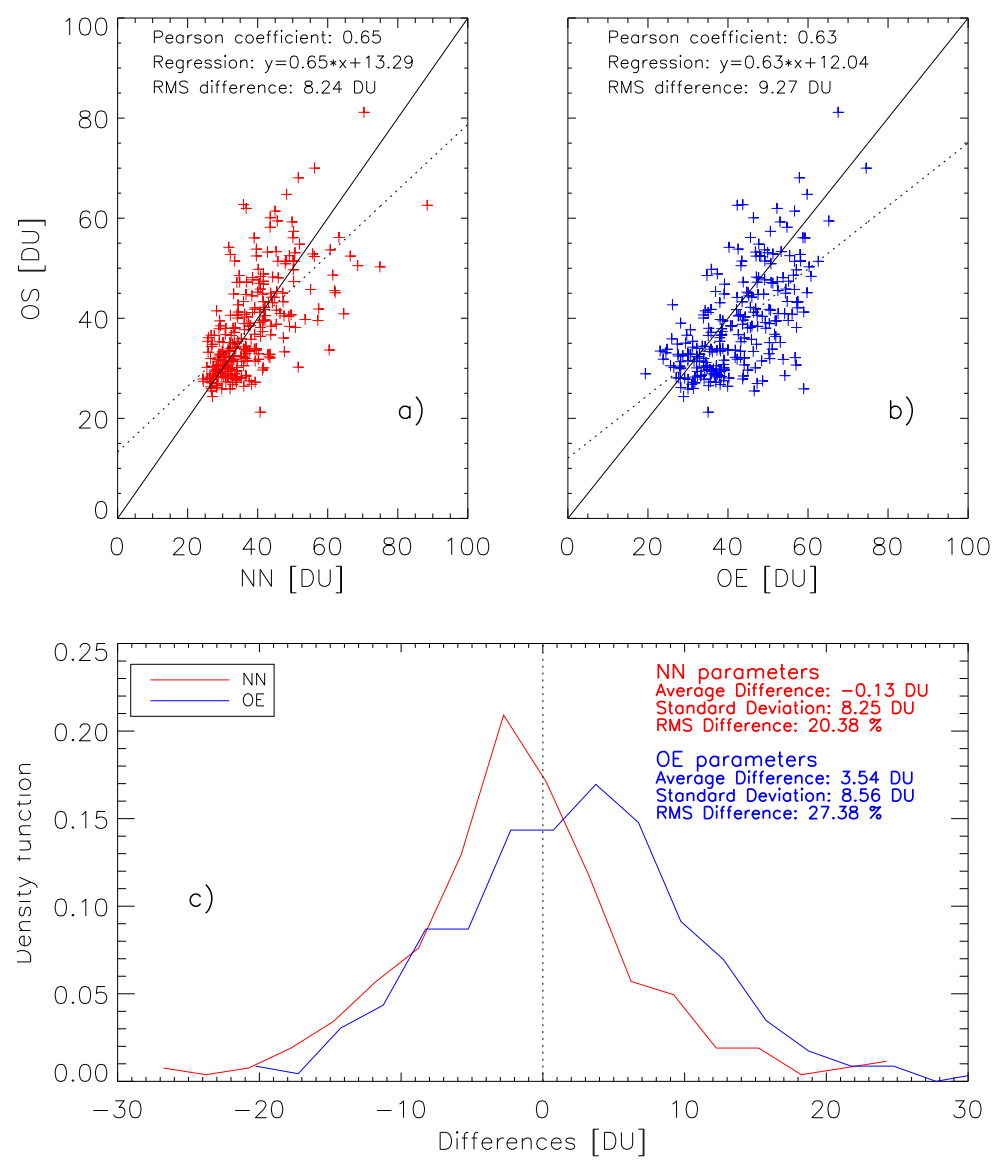

Fig. 6. Scatter plot of OMI-TOC NN retrievals (in red) and OE (in blue) versus corresponding OS true data (a), (b); histogram of the absolute deviations of OMI-TOC NN retrievals (in red) and OE (in blue) with respect to the OSs reference values, for the European points of the test data set. Statistical parameters are also reported (c).

\section{Sensitivity analysis}

\subsection{Analysis of outliers}

We examine the points in Fig. 3 with maximum distance from the 1:1 straight line. For these outliers, the ozone sonde profile is analyzed to understand if there are any systematic features that are useful for identifying specific weaknesses of our NN approach. Figure 10 shows three of these profiles. For most of the outliers, high vertical variability, with an additional peak of ozone concentration values in the upper troposphere, is observed. This includes the possible polar filament at Haute-Provence (France) station (first profile in Fig. 10). We observe a systematic underestimation of the retrieved TOCs with respect to the ozone sonde values when such enhancements in the ozone sonde profiles occur. We conclude that NNs may not be able to detect small scale vertical patterns in the troposphere, probably owing to a lack of vertical sensitivity inherent in the spectroscopic measurements that define the physical content of the measurements. This is also apparent from averaging kernels and smoothing errors in the OE algorithm development (Liu et al., 2010b).
More analyses over a greater data set will better characterize this issue.

\subsection{Sensitivity in the boundary layer}

We examine whether the OMI-TOC NN is able to extract information about ozone concentrations at the lowest altitudes from the radiance data. Recently it emerged that satellite ozone measurements might contain some useful information on planetary boundary layer (PBL). Kar et al. (2010) have shown, in particular, that OMI/MLS combined measurements with a TOR methodology can identify the signature of big cities, perhaps including the PBL contribution, even though sporadically. It is important to detect both urban and rural PBL information in TOC satellite measurements in order to better understand processes that can affect air quality and its monitoring on a continuous and global basis.

To investigate the NN's capability for the detection of information in the lowest layers of ozone, we train two different NNs for the retrieval of surface-506.625 hPa and surface- $759.937 \mathrm{hPa}$ ozone columns. The two top pressure levels, which define the first Umkehr layer and half of it, 

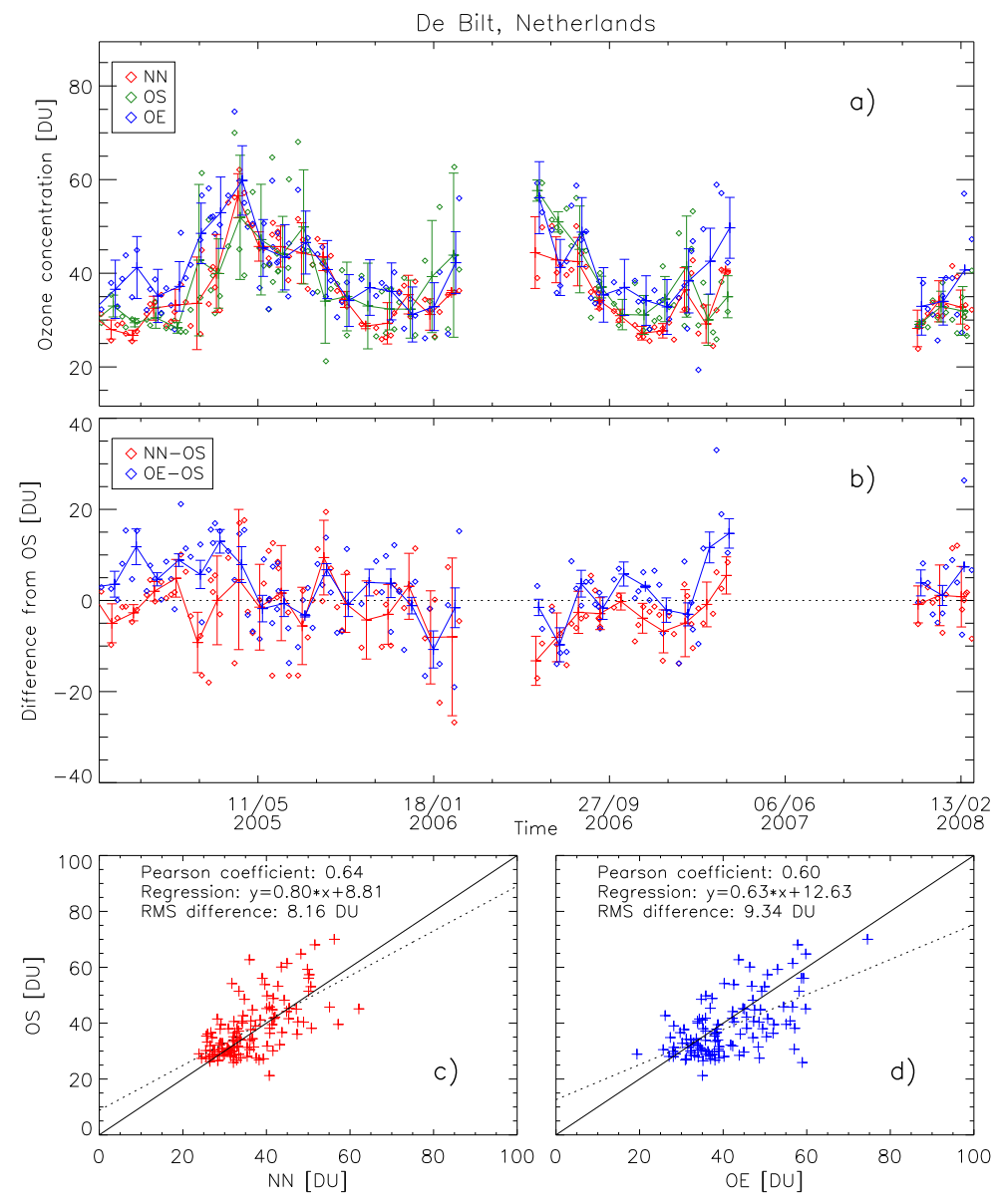

Fig. 7. Time series of OMI-TOC NN (in red) and OE (in blue) retrievals, and OS reference data (in green) (a); time series of absolute differences between OMI-TOC NN retrievals and OS (in red), and OE retrievals and OS (in blue). A monthly mean is over plotted (crosses with errorbars and lines) (b); scatter plot of OMI-TOC NN retrievals (in red) and OE (in blue) versus corresponding OS true data (c), (d) for De Bilt, the Netherlands.

respectively, correspond to about $5.5 \mathrm{~km}$ and $2.0 \mathrm{~km}$. The same training and test data sets and the same design methodology were used as for the surface- $200.0 \mathrm{hPa}$ column algorithm described in Sect. 2. As in Sect. 3, the retrievals were compared with the reference co-located ozone sondes columns over the test data set. In Fig. 11a and b the two scatter plots, surface- $506.625 \mathrm{hPa}$ and surface- $759.937 \mathrm{hPa}$, are shown. There is clearly some retrieval capability for the $0-5.5 \mathrm{~km}$ case, but the retrieval capability for $0-2.0 \mathrm{~km}$ is very poor: the dynamic range of the $\mathrm{NN}$ retrievals is very compressed and the correlation with ozone sondes columns is low. We also analyze the results of a further $\mathrm{NN}$ algorithm, designed with the same criteria, this time retrieving the $759.937-200.0 \mathrm{hPa}$ ozone column, i.e. the TOC of Sect. 2 without the lowest $2.0 \mathrm{~km}$. Figure $11 \mathrm{c}$ shows the scatter plot for this experiment. Comparing these results with those in Fig. 3, shows that while the correlations for the two plots are of a similar magnitude, the fitting line for the 759.937-200.0 hPa ozone column has both a bigger slope and a relevantly smaller intercept. Thus we are inclined to consider the signal from the PBL as a source of error, more than information, for NNs. We carried out a similar test with the retrievals from the Liu algorithm and also found out limited sensitivity to PBL ozone (Liu et al., 2010b), suggesting this is not a specific issue of the OMI-TOC NN.

\section{Conclusions}

We present a novel approach to retrieve tropospheric ozone columns at mid-latitudes from Ozone Monitoring Instrument radiance measurements based on a neural network algorithm (the OMI-TOC NN algorithm). The truth reference TOCs used to train the net are extracted from an extended set of ozone sondes measurements. The algorithm obtained has been tested over an independent data set by comparing retrievals to ozone sonde TOCs at campaign-based stations. The performance of the OMI-TOC NN is encouraging. The OMI-TOC NN results in this study are independent of clouds 

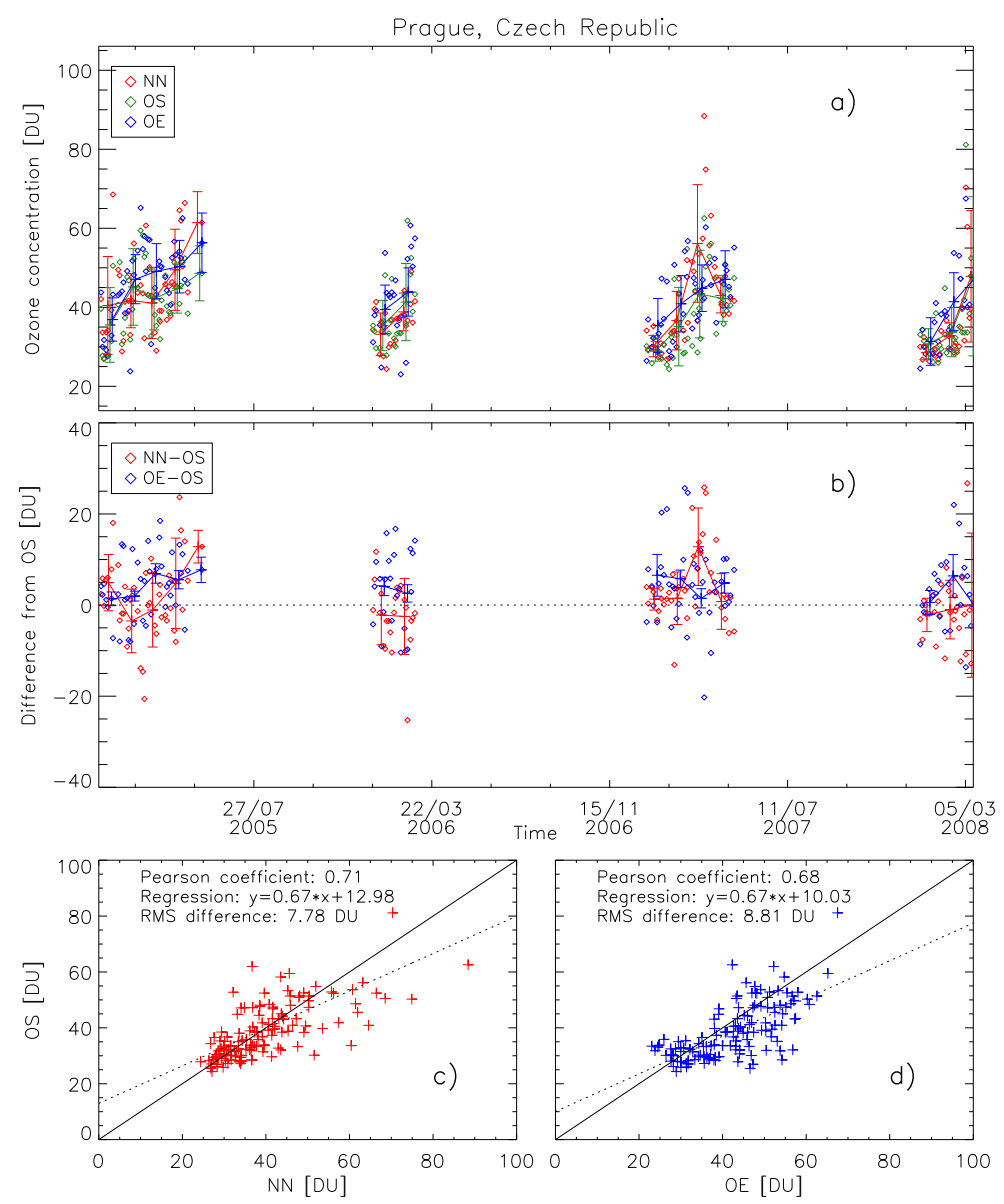

Fig. 8. Time series of OMI-TOC NN (in red) and OE (in blue) retrievals, and OS reference data (in green) (a); time series of absolute differences between OMI-TOC NN retrievals and OS (in red), and OE retrievals and OS (in blue). A monthly mean is over plotted (crosses with errorbars and lines) (b); scatter plot of OMI-TOC NN retrievals (in red) and OE (in blue) versus corresponding OS true data (c), (d) for Prague, Czech Republic.

and seasons. The accuracy is comparable to that of existing algorithms, including Schoeberl's tropospheric ozone residual (Schoeberl et al., 2007) and Liu's optimal estimation (Liu et al., 2010b) for similar mid-latitude data sets. The OMITOC NN gives better agreement with OS than the Liu algorithm at European test locations, i.e. our retrievals have a better correlation, a better fitting line, and lower RMS deviations. The Liu algorithm gives slightly better agreement for American test locations. The OMI-TOC NN has also shown a close-to-zero mean value of the differences with respect to ozone sonde reference TOCs, while about 2.0-3.5 DU were found in the case of Liu algorithm for the overall mid-latitudes and Europe, respectively. This effect can be due to the fact that the $\mathrm{NN}$ algorithm is trained by ozone sonde TOCs, while the Liu (and the Schoeberl) algorithm is physically independent from them. Please note that the performances of the OMI-TOC NN have been evaluated only at ozone sondes stations locations and future works will characterize the quality of our retrievals over extended areas, including, e.g. oceans. Please also note that our training data set is limited in time and a regular refresh of the NN coefficients by retraining with updated data sets is envisaged to maintain the OMI-TOC NN performances over time. The $\mathrm{NN}$ algorithm is much faster than OE-based algorithms, and so is preferable when large data sets of Level $1 \mathrm{~b}$ data have to be analyzed. However, the NN algorithm has been found unreliable in presence of small scale vertical patterns in the ozone vertical profile. A study of the sensitivity of the OMITOC NN to ozone at the lowest altitudes has shown that this algorithm has little sensitivity to planetary boundary layer ozone. Studied are planned to extend the training set with tropical and Southern Hemisphere samples and/or to develop dedicated algorithms which can be effectively used at different regions, i.e. with different climatologies. 

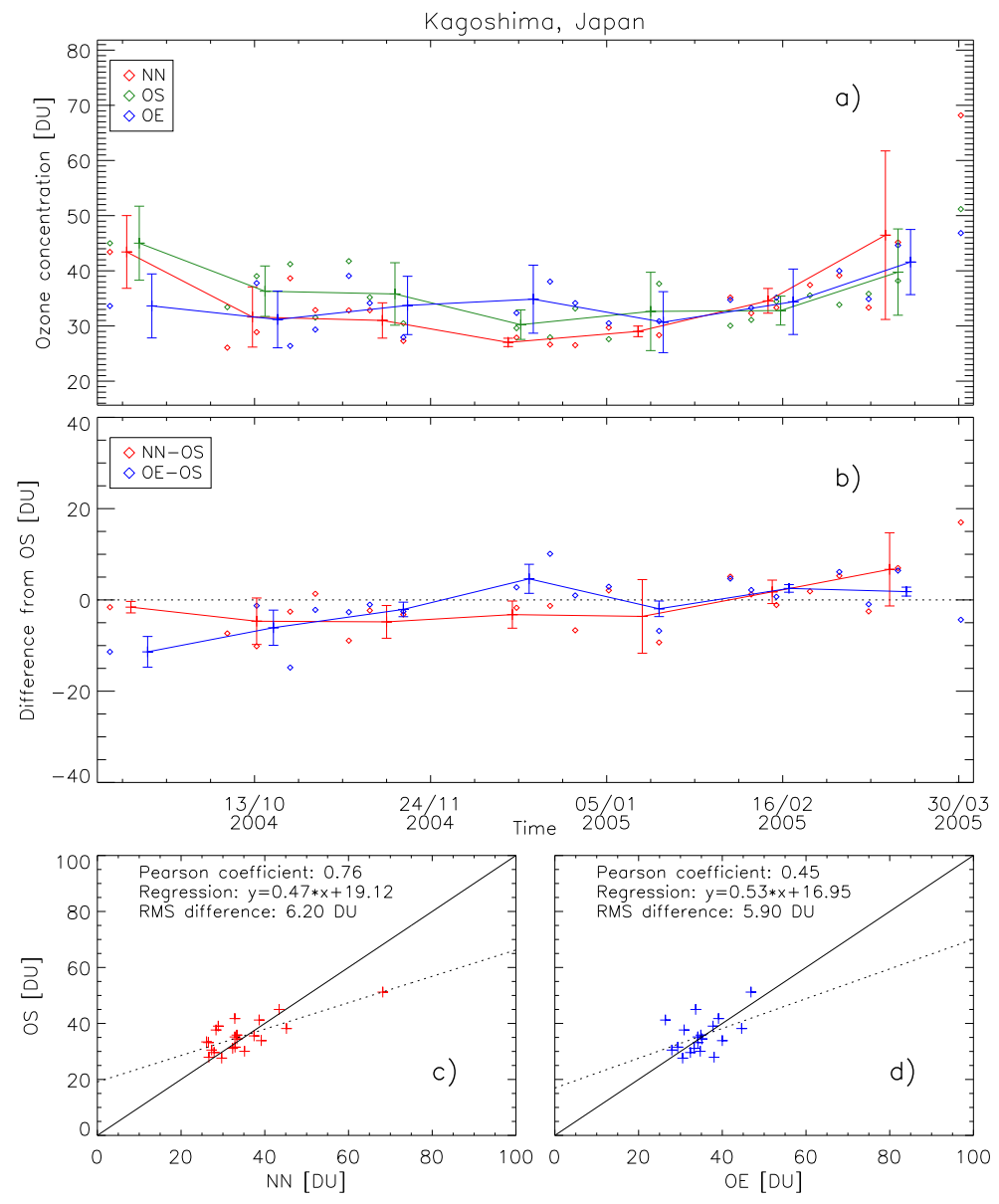

Fig. 9. Time series of OMI-TOC NN (in red) and OE (in blue) retrievals, and OS reference data (in green) (a); time series of absolute differences between OMI-TOC NN retrievals and OS (in red), and OE retrievals and OS (in blue). A monthly mean is over plotted (crosses with errorbars and lines) (b); scatter plot of OMI-TOC NN retrievals (in red) and OE (in blue) versus corresponding OS true data (c), (d) for Kagoshima, Japan.
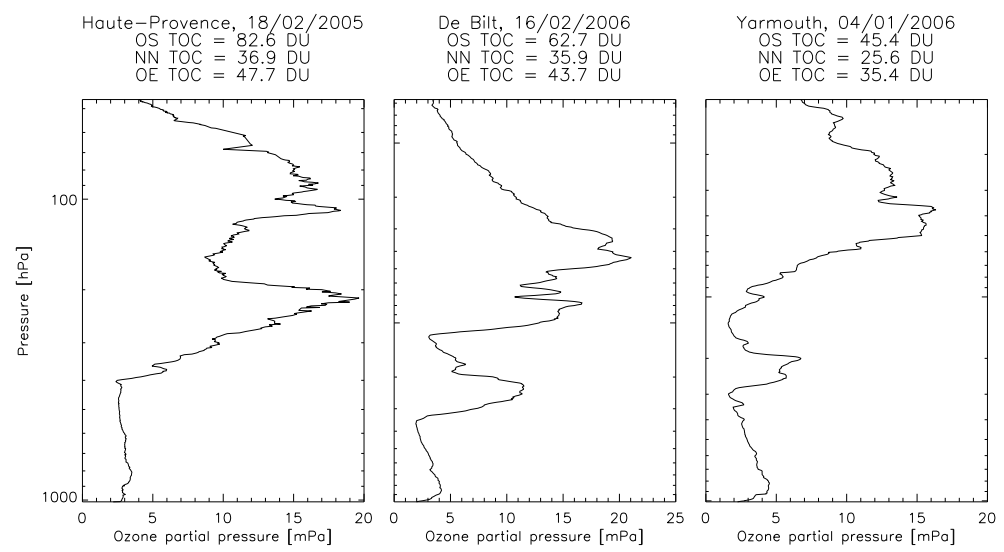

Fig. 10. OS concentration profiles at Haute-Provence, France, for 18 February 2005; De Bilt, the Netherlands, for 16 February 2006 ; Yarmouth, Canada, for 4 January 2006. TOC values from OS, NN and OE are also given. 

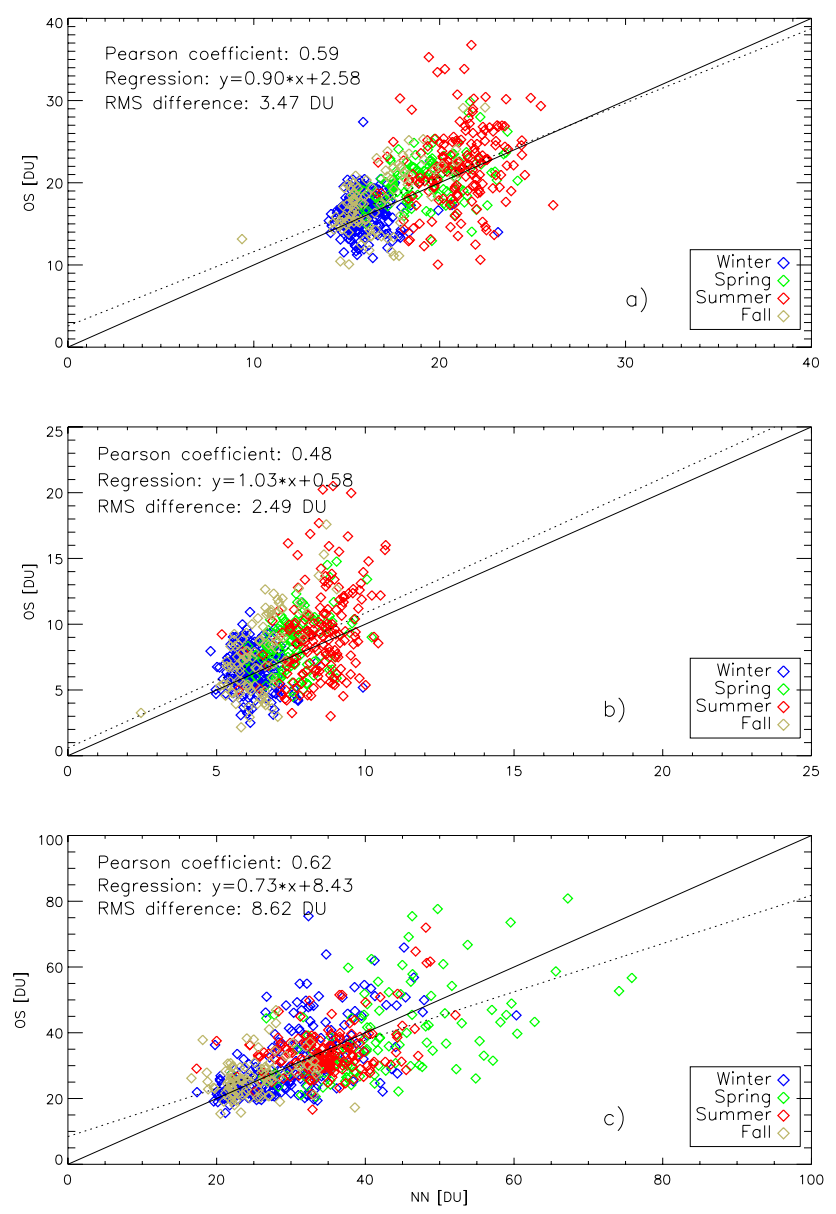

Fig. 11. Scatter plot of test NN retrievals versus corresponding OS values of the ozone columns in the altitude intervals: (a) surface to $506.625 \mathrm{hPa}$, (b) surface to $759.937 \mathrm{hPa}$, and (c) 759.937 to $200.0 \mathrm{hPa}$, for the test data set. Seasons are plotted in different colors (see legend).

Acknowledgements. The work has been financed by the the European Space Agency - Data User Element Innovators II APOLLO project. Research at the SAO was supported by the NASA grant NNX10AL51G and the Smithsonian Institution. All PIs of the OS stations used in this work are gratefully acknowledged. Christian Retscher and Michael Yan of AVDC are acknowledged for the precious support with correlative data.

Edited by: M. Weber

\section{References}

Bhartia, P. K. and Wellemeyer, G. C.: TOMS V8 total ozone algorithm in OMI algorithm theoretical basis document: OMI ozone products, Tech. Rep. 2, edited by: Bhartia, P. K., NASA Goddard Space Flight Center, Greenbelt, MD, USA, 2002.

Bishop, C. M.: Neural networks for pattern recognition, Oxford University Press, New York, USA, 1995.
Bovensmann, H., Burrows, J. P., Buchwitz, M., Frerick, J., Noël, S., Rozanov, V. V., Chance, K. V., and Goede, A. H. P.: SCIAMACHY - Mission objectives and measurement modes, J. Atmos. Sci., 56, 127-150, 1999.

Burrows, J. P., Weber, M., Buchwitz, M., Rozanov, V., Weissenmayer, A. L., Richter, A., DeBeek, R., Hoogen, R., Bramstedt, K., Eichmann, K. U., and Eisinger, M.: The global ozone monitoring experiment (GOME): Mission concept and first scientific results, J. Atmos. Sci., 56, 151-175, 1999.

Del Frate, F., Ortenzi, A., Casadio, S., and Zehner, C.: Application of neural algorithms for a real-time estimation of ozone profiles from GOME measurements, IEEE T. Geosci. Remote, 40, 22632270, 2002.

Del Frate, F., Iapaolo, M. F., Casadio, S., Godin-Beekmann, S., and Petitdidier, M.: Neural networks for the dimensionality reduction of GOME measurement vector in the estimation of ozone profiles, J. Quant. Spectrosc. Ra., 92, 275-291, 2005.

Fishman, J. and Larsen, J. C.: Distribution of total ozone and stratospheric ozone in the tropics: Implications for the distribution of tropospheric ozone, J. Geophys. Res., 92, 6627-6634, 1987.

Haykin, S.: Neural networks: A comprehensive foundation, 2nd Edn., Prentice Hall, Upper Saddle River, NJ, USA, 1999.

Hornik, K., Stinchcombe, M., and White, H.: Multilayer feedforward networks are universal approximators, Neural Netw., 2, 359-366, 1989.

Iapaolo, M., Godin-Beekmann, S., Del Frate, F., Casadio, S., Petitdidier, M., McDermid, I. S., Leblanc, T., Swart, D., Meijer, Y., Hansen, G., and Stebel, K.: Ozone profiles retrieved by neural network techniques: A global validation with lidar measurements, J. Quant. Spectrosc. Ra., 22, 1433-1440, 2005.

IPCC: Climate change 2001: The scientific basis, Third assessment of the Intergovernmental Panel on Climate Change, Working Group I report, Cambridge University Press, New York, NY, USA, 2001.

Jonson, J. E., Simpson, D., Fagerli, H., and Solberg, S.: Can we explain the trends in European ozone levels?, Atmos. Chem. Phys., 6, 51-66, doi:10.5194/acp-6-51-2006, 2006.

Kar, J., Fishman, J., Creilson, J. K., Richter, A., Ziemke, J., and Chandra, S.: Are there urban signatures in the tropospheric ozone column products derived from satellite measurements?, Atmos. Chem. Phys., 10, 5213-5222, doi:10.5194/acp-10-5213-2010, 2010.

Kecman, V.: Learning and soft computing, support vector machines, neural networks and fuzzy logic models, MIT Press, Cambridge, MA, USA, 2001.

Levelt, P. F., van den Oord, G. H. J., Dobber, M. R., Mlkki, A., Visser, H., de Vries, J., Stammes, P., Lundell, J. O. V., and Saari, H.: The Ozone Monitoring Instrument, IEEE T. Geosci. Remote, 44, 1093-1101, 2006.

Liu, X., Bhartia, P. K., Chance, K., Froidevaux, L., Spurr, R. J. D., and Kurosu, T. P.: Validation of Ozone Monitoring Instrument (OMI) ozone profiles and stratospheric ozone columns with Microwave Limb Sounder (MLS) measurements, Atmos. Chem. Phys., 10, 2539-2549, doi:10.5194/acp-10-2539-2010, 2010a.

Liu, X., Bhartia, P. K., Chance, K., Spurr, R. J. D., and Kurosu, T. P.: Ozone profile retrievals from the Ozone Monitoring Instrument, Atmos. Chem. Phys., 10, 2521-2537, doi:10.5194/acp-10-25212010, 2010b. 
Logan, J. A., Megretskaia, I. A., Miller, A. J., Tiao, G. C., Choi, D., Zhang, L., Stolarski, R. S., Labow, G. J., Hollandsworth, S. M., Bodeker, G. E., Claude, H., Muer, D. D., Kerr, J. B., Tarasick, D. W., Oltmans, S. J., Johnson, B., Schmidlin, F., Staehelin, J., Viatte, P., and Uchino, O.: Trends in the vertical distribution of ozone: A comparison of two analyses of ozonesonde data, J. Geophys. Res., 104, 26373-26399, 1999.

McPeters, R. D., Kroon, M., Labow, G. J., Brinksma, E., Balis, D., Petropavlovskikh, I., Veefkind, J. P., Bhartia, P. K., and Levelt, P.: Validation of the Aura Ozone Monitoring Instrument total column ozone product, J. Geophys. Res., 113, D15S14, doi:10.1029/2007JD008802, 2008.

Møller, M. F.: A scaled conjugate gradient algorithm for fast supervised learning, Neural Netw., 6, 525-533, 1993.

Müller, M. D., Kaifel, A. K., Weber, M., Tellmann, S., Burrows, J. P., and Loyola, D.: Ozone profile retrieval from Global Ozone Monitoring Experiment (GOME) data using a neural network approach (Neural Network Ozone Retrieval SYstem (NNORSY)), J. Geophys. Res., 108, 4497-4515, 2003.

Munro, R., Siddans, R., Reburn, W. J., and Kerridge, B. J.: Direct measurement of tropospheric ozone distributions from space, Nature, 392, 171-198, 1998.

Oltmans, S., Lefohn, A., Harris, J., Galbally, I., Scheel, H., Bodeker, G., Brunke, E., Claude, H., Tarasick, D., Johnson, B., Simmonds, P., Shadwick, D., Anlauf, K., Hayden, K., Schmidlin, F., Fujimoto, T., Akagi, K., Meyer, C., Nichol, S., Davies, J., Redondas, A., and Cuevas, E.: Long-term changes in tropospheric ozone, Atmos. Environ., 40, 3156-3173, doi:10.1016/j.atmosenv.2006.01.029, 2006.

Rodgers, C. D.: Inverse methods for atmospheric sounding: Theory and practice, World Scientific Publishing Company, London, UK, 2000.

Schoeberl, M. R., Ziemke, J. R., Bojkov, B., Livesey, N., Duncan, B., Strahan, S., Froidevaux, L., Kulawik, S., Bhartia, P. K., Chandra, S., Levelt, P. F., Witte, J. C., Thompson, A. M., Cuevas, E., Redondas, A., Tarasick, D. W., Davies, J., Bodeker, G., Hansen, G., Johnson, B. J., Oltmans, S. J., Vömel, H., Allaart, M., Kelder, H., Newchurch, M., Godin-Beekmann, S., Ancellet, G., Claude, H., Andersen, S. B., Kyrö, E., Parrondos, M., Yela, M., Zablocki, G., Moore, D., Dier, H., von der Gathen, P., Viatte, P., Stübi, R., Calpini, B., Skrivankova, P., Dorokhov, V., de Backer, H., Schmidlin, F. J., Coetzee, G., Fujiwara, M., Thouret, V., Posny, F., Morris, G., Merrill, J., Leong, C. P., Koenig-Langlo, G., and Joseph, E.: A trajectory-based estimate of the tropospheric ozone column using the residual method, J. Geophys. Res., 112, D24S49, doi:10.1029/2007JD008773, 2007.

Seinfeld, J. H. and Pandis, S. N.: Atmospheric chemistry and physics: from air pollution to climate change, J. Wiley and sons, New York, NY, USA, 1998.

Sellitto, P., Burini, A., Del Frate, F., and Casadio, S.: Dedicated neural networks algorithms for direct estimation of tropospheric ozone from satellite measurements, in: Proceedings of International Geosciences and Remote Sensing Symposium, 2007a.

Sellitto, P., Del Frate, F., and Burini, A.: Neural networks algorithms for the retrieval of ozone concentration profiles from Envisat-SCIAMACHY measurements, in: Proceedings of Envisat Symposium, 2007b.
Sellitto, P., Del Frate, F., Solimini, D., Retscher, C., Bojkov, B., and Bhartia, P. K.: Neural networks algorithms for ozone profile retrieval from ESA-Envisat SCIAMACHY and NASA-Aura OMI satellite data, in: Proceedings of International Geosciences and Remote Sensing Symposium, 2008.

Sellitto, P., Solimini, D., Del Frate, F., and Casadio, S.: Tropospheric ozone column retrieval from ESA-Envisat SCIAMACHY nadir UV/VIS radiance measurements by means of a neural network algorithm, IEEE T. Geosci. Remote, doi:10.1109/TGRS.2011.2163198, in press, 2011.

Shindell, D. T., Faluvegi, G., Koch, D. M., Schmidt, G. A., Unger, N., and Bauer, S. E.: Improved Attribution of Climate Forcing to Emissions, Science, 326, 716-718, doi:10.1126/science.1174760, 2009.

Stajner, I., Wargan, K., Pawson, S., Hayashi, H., Chang, L.-P., Hudman, R. C., Froidevaux, L., Livesey, N., Levelt, P. F., Thompson, A. M., Tarasick, D. W., Stübi, R., Andersen, S. B., Yela, M., König-Langlo, G., Schmidlin, F. J., and Witte, J. C.: Assimilated ozone from EOS-Aura: Evaluation of the tropopause region and tropospheric columns, J. Geophys. Res., 113, D16S32, doi:10.1029/2007JD008863, 2008.

The Royal Society: Science Policy Report 15/08, Ground-level ozone in the 21 st century: future trends, impacts and policy implications, Tech. rep., The Royal Society, London, UK, 2008.

Thompson, A. M., Witte, J. C., McPeters, R. D., Oltmans, S. J., Schmidlin, F. J., Logan, J. A., Fujiwara, M., Kirchhoff, V. W. J. H., Posnym, F., Coetzee, G. J. R., Hoegger, B., Kawakami, S., Ogawa, T., Johnson, B. J., Vmel, H., and Labow, G.: Southern Hemisphere ADditional OZonesondes (SHADOZ) 1998-2000 tropical ozone climatology 1. Comparison with Total Ozone Mapping Spectrometer (TOMS) and ground-based measurements, J. Geophys. Res., 108, 8238, doi:10.1029/2001JD000967, 2003.

Twomey, S.: Introduction to the mathematics of inversion in remote sensing and indirect measurements, Dover Publications Inc., Mineola, NY, USA, 1996.

Valks, P. J. M., Koelemeijer, R. B. A., van Weele, M., van Velthoven, P., Fortuin, J. P. F., and Kelder, H.: Variability in tropical tropospheric ozone: Analysis with Global Ozone Monitoring Experiment observations and a global model, J. Geophys. Res., 108, 4328, doi:10.1029/2002JD002894, 2003.

Vingarzan, R.: A review of surface ozone background levels and trends, Atmospheric Environment, 38, 3431-3442, doi:10.1016/j.atmosenv.2004.03.030, 2004.

WMO: Scientific assessment of ozone depletion: 2002, Executive Summary, Tech. Rep. 47, World Meteorological Organization, Geneva, Switzerland, 2002.

Yang, Q., Cunnold, D. M., Wang, H. J., Froidevaux, L., Claude, H., Merrill, J., Newchurch, M., and Oltmans, S. J.: Midlatitude tropospheric ozone columns derived from the Aura Ozone Monitoring Instrument and Microwave Limb Sounder measurements, J. Geophys. Res., 112, D20305, doi:10.1029/2007JD008528, 2007.

Ziemke, J. R., Chandra, S., and Bhartia, P. K.: Two new methods for deriving tropospheric column ozone from TOMS measurements: Assimilated UARS MLS/HALOE and convective cloud differential techniques, J. Geophys. Res., 103., 115-122, 1998. 
Ziemke, J. R., Chandra, S., Duncan, B. N., Froidevaux, L., Bhartia, P. K., Levelt, P. F., and Waters, J. W.: Tropospheric ozone determined from Aura OMI and MLS: Evaluation of measurements and comparison with the Global Modeling Initiative's Chemical Transport Model, J. Geophys. Res., 111, D19303, doi:10.1029/2006JD007089, 2006a.
Ziemke, J. R., Chandra, S., Duncan, B. N., Froidevaux, L., Bhartia, P. K., Levelt, P. F., and Waters, J. W.: Tropospheric ozone determined from Aura OMI and MLS: Evaluation of measurements and comparison with the Global Modeling Initiative's Chemical Transport Model, J. Geophys. Res., 111, D19303, doi:10.1029/2006JD007089, 2006b. 